\title{
Japan's researchers merit further reforms
}

The new batch of changes to procedures for selecting competitive grants is one of many recent welcome improvements to Japan's university research system. But it is by no means adequate.

JAPAN'S university researchers have good cause to be more optimistic about the future. After years of neglect, their government has in the past year introduced substantial new sources of research funds from ministries and agencies other than the Ministry of Education, Science, Sports and Culture (Monbusho), breaking that ministry's stranglehold on university research. On top of this, Monbusho itself has almost doubled the budget for its competitive research grants in the past five years bringing this source of funds up to a much more healthy $¥ 100$ billion (about US\$1 billion) a year. And now Monbusho’s Science Council, comprising leading academics, has introduced some much needed reforms (see page 573) to make the ministry's system of grant selection more open, fair and transparent.

This extra funding and the reforms across the whole system of government support for research are indeed welcome, and there can be little doubt that the changes will boost the output and quality of Japan's basic research. Nevertheless, much still remains to be done to improve the lot of Japan's university researchers.

One glaring problem that needs to be tackled is the chronic lack of technicians in the universities. Many years ago, the Japanese government decided to follow the lead of governments in the West and started to reduce the number of government employees. Smaller government was rightly seen as more efficient and as one way of tackling the swelling sea of red ink in government finances. But it has had disastrous consequences for university research.

Each year, the universities and Monbusho's university-related research institutes have to reduce their number of employees by a fixed percentage. This has largely been achieved by cutting technical rather than academic positions. Further exacerbating the problem are Monbusho's rigid rules on the salaries that can be paid to technicians. Technicians have always been treated as second-class citizens in Japan's universities and salaries are not competitive with those in industry. As a result, universities cannot attract highquality technicians to the few posts still available. The decline in technical support has meant that an increasing burden of menial and technical tasks has fallen on young researchers, distracting them from creative research. Furthermore, expensive equipment is inadequately maintained, and safety is often compromised.

Those pushing for reform of the university system have some ideas about how the technician problem could be solved. One worthy of consideration is a proposal from Akito Arima, former president of Tokyo University, that large numbers of research assistant (josh $u$ ) positions, the lowest tenured academic rank in the university system, should be given to technicians, and the employment needs of young researchers should instead be met with more postdoctoral positions. With the government now planning to double the number of postdoctoral positions to 10,000 by the end of the

\section{Washington move}

The Nature editorial office in Washington DC will be at the following address from Monday 20 February:

968 National Press Building,

Washington DC 20045-1938

Telephone, fax and e-mail remain the same. decade, Arima's idea is becoming a practical proposition.

The reforms of the ministry's competitive grant system are another step in the right direction that should provide young researchers with a better chance of success in their grant applications. But here too, much could still be done. One obvious improvement would be the provision of feedback on rejected grant applications. The present system, even with the reforms (which will be implemented soon), can be likened to a black hole. Applications go into the system but nothing comes out except a 'yes' or 'no'. As the majority of applications fail, this is demoralizing for researchers who do not know why their application failed or how close they came to the mark. The ministry's excuse that there are too many applications to provide feedback is lame, particularly when the Internet is there to allow information to be readily forwarded by e-mail.

Some exposure of Monbusho's grant screening process to scrutiny by non-Japanese scientists, as some are suggesting, would undoubtedly be healthy and could lead to a better and fairer system more in line with international standards. The ministry's excuse (and the excuse of review committee members) that there would be language problems is inadequate, at least for the ministry's larger grants, which are supposed to support "internationally recognized research". For these, assessment involving non-Japanese scientists would seem to be a prerequisite.

\section{Values poisoned by commerce}

A survey and a 'leak' are symptoms of a corruption of traditional science.

OPENNESS and trust are traditional virtues of science, which its defenders and celebrators like to emphasize. In the end, reproducibility and falsifiability are the principal characteristics of the discipline, but in the practice of science these are intimately bound up with its cultural values. That the ideal is often undermined by personal ambition and commercial confidentiality is a misfortune that science has weathered over the centuries, whereas collisions with religious authorities and dictators have presented deeper threats. Another is emerging within molecular biology.

Today's fundamental elucidation of a protein interaction can be (almost literally) tomorrow's profit-earning test kit. Today's gene sequence, if not applicable tomorrow, may be assumed to be replete with vast profits achievable the day after. A survey (see page 574) shows that companies are acting on such assumptions, as their shareholders would no doubt insist they should. Rumours suggest that some individuals are doing the same (see page 574), as their colleagues would insist they should not. Although commerce is to be supported, there are signs of a culture being made sick by commercial interests to an extent that is unprecedented in science. The sociologists have a boom time ahead of them analysing the symptoms, but there is no sign of a cure, and the costs will have to be borne by everybody involved as the culture changes to one of legalistic precaution. Gallingly, those costs will serve to subsidize the relative few who make the profits. 